\title{
Being Pregnant and Diagnosed with Breast Cancer
}

\author{
Sibylle Loibl ${ }^{a, b}$ Sileny N. Han ${ }^{c}$ Frederic Amant ${ }^{c}$ \\ ${ }^{a}$ German Breast Group, Neu-Isenburg, ${ }^{b}$ Städtisches Klinikum Offenbach, Germany \\ 'Multidisciplinary Breast Cancer Center, Leuven Cancer Institute, UZ Gasthuisberg, Leuven, Belgium
}

\section{Keywords}

Breast cancer · Pregnancy · Chemotherapy · Guidelines

\section{Summary}

Breast cancer during pregnancy $(B C P)$ is an important subgroup within the young and very young breast cancer patients. It accounts for about $1 \%$ of all breast cancers. Due to an increased awareness, the attitude towards breast cancer during pregnancy has changed and, today, women with BCP are more likely to receive standard chemotherapy and have a term delivery instead of being advised to interrupt the pregnancy or undergo an early preterm delivery. This increased knowledge is based on small cohort studies and international collaborations such as the registry by the German Breast Group for BCP and the initiative of the European Society of Gynaecological Oncology (ESGO). Guidelines and recommendations such as the German guidelines by the AGO (Arbeitsgemeinschaft Gynäkologische Onkologie, www.ago-online.org) and the National Comprehensive Cancer Network (NCCN) guidelines include recommendations for BCP. In general, surgery and chemotherapy (beyond the 13th week of gestation) can be safely performed during pregnancy. Chemotherapy should follow the treatment recommendations for breast cancer in young women. Trastuzumab, endocrine treatment, and radiotherapy are not indicated during pregnancy. Preterm delivery should be avoided as far as possible because it bears a higher risk of infant morbidity and mortality. The treatment of BCP should be planned within a multidisciplinary team including perinatologists, obstetricians and neonatologists.

\author{
Schlüsselwörter \\ Mammakarzinom - Schwangerschaft - Chemotherapie · \\ Leitlinien
}

\section{Zusammenfassung}

Das Mammakarzinom in der Schwangerschaft ist mit 1\% aller Mammakarzinome selten. Es bildet jedoch einen wichtigen Aspekt der jungen und sehr jungen Frauen mit Mammakarzinom. Ein gesteigertes Bewusstsein für diese seltene Koinzidenz hat dazu beigetragen, dass die Frauen heute mit höherer Wahrscheinlichkeit eine Standardtherapie erhalten und nicht vorzeitig entbunden werden. Es wird seltener, dass den Frauen zu einem Schwangerschaftsabbruch geraten oder ihnen eine vorzeitige Entbindung anempfohlen wird. Unser heutiges Wissen stammt aus kleinen Kohortenstudien, aber auch aus internationalen Registern wie das der German Breast Group zum Mammakarzinom in der Schwangerschaft oder der Initiative der ESGO (European Society of Gynaecological Oncology). Leitlinien zum Mammakarzinom wie die der Arbeitsgemeinschaft Gynäkologische Onkologie (AGO, www.ago-online.org) oder des NCCN (National Comprehensive Cancer Network) beinhalten auch Abschnitte zur Erkrankung während der Schwangerschaft. Ganz allgemein gilt, dass Operationen und Chemotherapien (jenseits der 13. Schwangerschaftswoche), die sich an den Therapieleitlinien für Nicht-Schwangere möglichst nah anlehnen, auch während der Schwangerschaft durchgeführt werden können. Die Hormontherapie, Trastuzumab und die Bestrahlung werden erst nach der Entbindung initiiert. Eine vorzeitige Entbindung mit dem Risiko, die Morbidität und Mortalität des Kindes zu erhöhen, sollte weitestgehend vermieden werden. Um dies zu erreichen, müssen diese Patientinnen in einem interdisziplinären Team, dem auch Perinatologen, Geburtshelfer und Neonatologen angehören, beraten und behandelt werden.

\section{KARGER \\ Fax +49 7614520714 \\ Information@Karger.de}

www.karger.com (c) 2012 S. Karger GmbH, Freiburg

$1661-3791 / 12 / 0073-0204 \$ 38.00 / 0$

Accessible online at:

www.karger.com/brc
Prof. Dr. med. Dr. Sibylle Loibl

GBG-Forschungs-GmbH

Martin-Behaim-Strasse 12

63236-Neu-Isenburg, Germany

Tel. +49 6102 79874-26, Fax -18

Sibylle.Loibl@germanbreastgroup.de 


\section{Introduction}

Breast cancer during pregnancy (BCP) accounts for approximately $2 \%$ of primary breast cancer patients [1]. The term $\mathrm{PABC}$, for pregnancy-associated breast cancer, refers to all cancers diagnosed during pregnancy up to 1 year after delivery. Here, we will focus on BCP as these women need to be treated under special circumstances. The incidence seems to increase because women tend to postpone childbearing to their thirties [2,3].

The median age of women diagnosed with $\mathrm{BCP}$ is below 35 years [4]. But the biology of breast cancer in very young women has a more aggressive phenotype $[5,6]$. This partly explains why young women have an inferior prognosis compared to women with the same biological subtype but at an older age [7]. Whether women with breast cancer in pregnancy have a worse prognosis compared to women of the same age and with the same tumour features has not yet been sufficiently answered [8].

Today's credo is to treat pregnant women with breast cancer as closely as possible to standards for young, non-pregnant women with breast cancer $[9,10]$. Data are few but increasing in number to support this statement. Early preterm deliveries with a high risk of foetal morbidity and mortality are in general not indicated [11]. The general recommendation is to treat the women during pregnancy and deliver as closely as possible to term [12]. This requires local therapy, but also systemic therapy during pregnancy.

\section{Diagnostics}

Routine examination of the breast is not part of the general examinations for pregnant women, in contrast to the Papanicolaou test (Pap smear) for early detections of cervical cancer. There are no typical signs or symptoms for BCP. BCP is not screen detected because general screening is not indicated in this age group. Signs and symptoms should not be neglected and a lump should be biopsied for histology if it does not disappear after 4 weeks, to avoid unnecessary delays in the right diagnosis and treatment, even if $80 \%$ of breast biopsies performed in pregnant women will prove to be benign. Core biopsy is the standard procedure to obtain tissue. Fine-needle biopsy/aspiration cytology is not recommended. However, a 1-month delay in diagnosis can increase the risk of nodal involvement by 0.9 to $1.8 \%$ [13].

\section{Imaging}

Ultrasound is the routine imaging method during pregnancy and a first step to differentiate between a solid mass and normal but dense breast tissue, even if the sensitivity might be lower than in non-pregnant women [14]. Bilateral mammo- graphy to assess microcalcifications, multi-centric or bilateral disease is recommended despite radiation. With adequate abdominal shielding, the radiation dose delivered to the foetus is below $0.01 \mathrm{~Gy}$ and the risk for the foetus is minimal [15]. Data from the UK childhood cancer study demonstrate that there is no significantly increased risk to develop childhood cancer or leukaemia if the child was exposed to diagnostic radiation in utero [16]. There are little data on the sensitivity of breast magnetic resonance imaging (MRI), but it is generally not recommended during pregnancy if gadolinium is needed. Gadolinium has the ability to cross the placental barriers and the foetal risks are not well known [17].

The same is true for staging procedures during pregnancy. Primary metastatic disease is rare and accounts for less than $10 \%$ in the general breast cancer population. The general rule is that the foetus should not be unnecessarily exposed to radiation exposure. If the outcome of the diagnostic procedures will have an impact on therapeutic decisions, imaging should be performed. However, a bone scan should be avoided; instead, a non-contrast-enhanced bone MRI can be performed. In case MRI is not available or indicated, a bone scan with a bladder catheter may be performed. Ultrasound of the liver, lymph nodes and breast or a chest X-ray can be performed safely.

\section{Pathology}

In general, breast cancer in young women seems to have different and more aggressive phenotypes than breast cancer in elderly women. However, breast cancer diagnosed during pregnancy seems comparable to breast cancer in young nonpregnant women. However, there are also reports stating the opposite. More than $90 \%$ of the women have a ductal invasive carcinoma, mostly undifferentiated and without hormone receptor expression. The rate of HER2-positive cancers may be higher, at least in some series [4, 9].

\section{Treatment}

The German guidelines by the AGO-Kommission Breast (AGO = Arbeitsgemeinschaft Gynäkologische Onkologie) and the National Comprehensive Cancer Network (NCCN) guidelines refer, in a separate chapter, to breast cancer in pregnancy $[18,19]$. Both guidelines clearly state that patients with BCP should be treated as closely as possible to standard recommendations for non-pregnant young women. The AGO guidelines are more detailed in terms of obstetrical advice, whereas the NCCN guidelines stick to the pure treatment algorithms, which are very similar in both guidelines (table 1). Taking into account recently published data, recommendations and publicly available guidelines, a general therapy algorithm has been formed (fig. 1). 
Table 1. Comparison between available international guidelines for $\mathrm{BCP}$ as part of the breast cancer guidelines

\begin{tabular}{|c|c|c|}
\hline & AGO recommends/includes & NCCN recommends/includes \\
\hline Termination & not mentioned & to discuss in 1 st trimester \\
\hline Diagnostic measures & as in non-pregnant women; no MRI & no mentioned \\
\hline Surgery & as in non-pregnant women & as in non-pregnant women \\
\hline SLN & radiolabelled marker, no blue dye & radiolabelled sulphur colloids, no blue dye \\
\hline Radiotherapy & no RT during pregnancy but postpartum & no RT during pregnancy but postpartum \\
\hline Chemotherapy & $\begin{array}{l}\text { only after the } 1 \text { st trimester; } \mathrm{A} / \mathrm{EC} /(\mathrm{F}) \mathrm{A} / \mathrm{EC} \text {; } \\
\text { taxane possible; no MTX }\end{array}$ & $\begin{array}{l}\text { only after the 1st trimester; FAC; paclitaxel } \\
\text { weekly }\end{array}$ \\
\hline Trastuzumab & no - postpartum & no - postpartum \\
\hline Endocrine therapy & no - postpartum & no - postpartum \\
\hline Obstetrical advice & yes & no \\
\hline Lactation & yes & no \\
\hline Prognosis & yes & no \\
\hline
\end{tabular}

MRI = Magnetic resonance imaging; SLN = sentinel lymph node; $\mathrm{RT}=$ radiotherapy; $\mathrm{A}=$ doxorubicin; $\mathrm{E}=$ epirubicin; $\mathrm{C}=$ cyclophasphamide; $\mathrm{F}=$ fluorouracil; MTX = methotrexate.

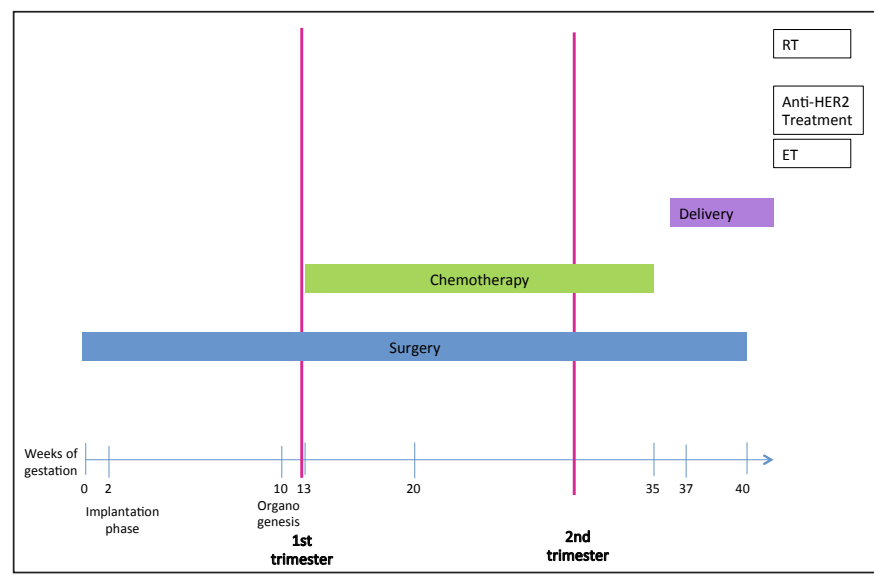

Fig. 1. Treatment modalities in relation to gestational age weeks $2-10$ : implantation (0-2 weeks), organogenesis (2-10 weeks), foetal phase (> 10 weeks). Chemotherapy starting from 13-14 weeks allows for a 'safety period'.

\section{Local Therapy}

Breast-conserving surgery is a valid option during pregnancy. The indication pro or contra breast-conserving surgery should be taken as in non-pregnant women; however, mastectomy is not automatically indicated as the preferred treatment option. The major difference between these two surgical modalities is the need for radiotherapy after breast-conserving surgery, to avoid local recurrences. On the other hand, chemotherapy is usually indicated in this age group, and radiotherapy can then be safely postponed to the postpartum period.

Dominici et al. [20] analysed the incidence of wound healing complications after surgery in 67 patients with PABC, of which 20 patients underwent conservative breast surgery. There were 4 cases ( $9 \%$ ) of post-operative cellulitis, 1 case of breast haematoma and 1 case of an axillary abscess; these were all managed on an outpatient basis. With a mean followup of 62 months, there were no loco-regional recurrences noted in the breast conservation group.

In recent years, sentinel node biopsy has been proven to be indicated as staging procedure and as an alternative to axillary dissection in certain indications. The general recommendation is to use a 1-day protocol with radiolabelled colloid as tracer, but not blue dye [10]. It could be demonstrated by Gentilini et al. [21] that $99 \mathrm{mTc}$ sulphur colloid is concentrated only in the injection site and in the lymph nodes, with negligible irradiation to other tissues and organs. Blue-dye mapping is not recommended alone, but only in combination with radiolabelled tracers. Isosulfan blue dye has a possible risk of maternal anaphylaxis, which can also be harmful to the foetus [22]. Methylene blue dye has no documented anaphylactic hypersensitivity reactions, it has been used in the past as a diagnostic tool in pregnancy; however, foetal exposure was associated with digestive tract malformations and foetal demise. A recent small study measured the pharmacokinetics of methylene blue dye in 10 non-pregnant women and extrapolated the results to estimate the foetal exposure. Measurements in plasma and urine indicated that the blue dye was quickly distributed from the breast injection site to the circulation, with $32 \%$ of the total dose excreted in the urine within $48 \mathrm{~h}$. Combined with existing data on organ distribution of methylene blue, the estimated maximal dose to the foetus is probably only $0.25 \mathrm{mg}$ ( $5 \%$ of the administered dose) and may be further reduced by other physiologic factors related to pregnancy [23]. Nevertheless, data are limited and it remains an individual decision.

\section{Radiotherapy}

In general, radiotherapy is not indicated during pregnancy. Post-operative radiotherapy is used in breast cancer treatment to minimise the risk of local recurrence. If no chemotherapy is given, this should start within 12 weeks of surgery. Any delay in treatment increases the likelihood of future metastases at a rate of $0.028-0.057 \%$ per day [24]. Radiotherapy has long been considered incompatible with pregnancy; however, a recent review supports its use during pregnancy, in cases where the treatment field was distant from the gravid uterus [25]. Radiotherapy has been utilised during pregnancy in the treatment of breast cancer, Hodgkin's disease, thyroid cancer, brain tumours and head and neck cancer. The dose to the foetus comes from 3 principal sources: photon leakage through the treatment head of the machine, radiation scattered from the collimators and beam modifiers, and radiation 
scattered within the patient from the treatment beams [26] Concerning the first 2 sources of radiation reaching the foetus, the dose can easily be reduced by a factor of $2-4$ by proper abdominal shielding. The American Association of Physicists in Medicine (AAPM) published guidelines on the estimation and reduction of the foetal dose [26]. Radiation exposure to the foetus can cause foetal malformations, growth restriction, microcephaly, mental retardation and foetal demise (deterministic effects, dose related), and also a greater risk of secondary malignancies (stochastic effects).

\section{Systemic Treatment}

Breast cancer in very young women is almost always treated with cytotoxic agents as part of the systemic therapy. The type of adjuvant or neoadjuvant chemotherapy, however, does not differ depending on age. It seems that young women benefit from neoadjuvant therapy also in terms of improved overall survival [27]. The standard (neo)adjuvant chemotherapy regimen today comprises anthracycline/taxane-based therapy, either as combination or as sequential therapy. Dose-dense therapy seems to be superior, especially in hormone receptornegative disease [28]. The TAC regimen (docetaxel, doxorubicin, cyclophosphamide), which is very effective in young women with triple-negative breast cancer, reaching a pathological complete response rate in almost $60 \%$, has not been proven in the adjuvant setting to be better than a sequential regimen $[29,30]$. However, it is more toxic. The general rule is 'as little as possible, but as much as needed'. The teratogenicity and toxicity of any drug during pregnancy depends strongly on the trimester of the pregnancy and on the dosage. Anthracyclines are accepted as chemotherapy for young women during pregnancy, whereas taxanes are not. In addition, taxanes are very often not even recommended during pregnancy. However, the data for taxanes are increasing, and the smaller cohorts treated by taxanes during pregnancy do not indicate a worse outcome for children exposed to a taxane in utero than for anthracyclines [31]. In addition, in a pregnant-baboon model, the placenta appears to filter cytotoxic drugs, especially taxanes. A low transfer of $<3 \%$ was observed for paclitaxel in the baboon model [32]. Therefore, the AGO and NCCN guidelines do not exclude taxanes as part of the chemotherapy during pregnancy. Very often, when using a sequential regimen, the taxane will not be given during pregnancy. On the other hand, weekly paclitaxel is very well tolerated. Standard regimens to be used in pregnancy are, e.g., FEC $\times 6$ (5-fluorouracil, epirubicin, cyclophosphamide), FEC-docetaxel (FEC-Doc), E(A)C-Doc (etoposide, (epirubicin,) cyclophosmphamide-docetaxel), or $\mathrm{E}(\mathrm{A}) \mathrm{C}$-paclitaxel weekly. 'Chemo-light' with reduced cycles and agents, e.g., epirubicin monotherapy or 4xTC (docetaxel, cyclophosphamide), if not completed after delivery is not indicated. Also CMF (cyclophosphamide, methotrexate, 5-fluorouracil) alone is not considered to be standard of care anymore. No experimental regimen and agents should be used, e.g. nab-Paclitaxel, since they are also not indicated for non-pregnant primary breast cancer patients. It seems that chemotherapy-induced side effects are fewer or less pronounced in pregnant than in non-pregnant women, especially nausea and vomiting, but also haematological side effects. This could be due to the pregnancy-attributed physiological changes, but also to the chemotherapy effect during pregnancy. So far, we have no data to support one or the other hypothesis. A French group extrapolated that $\mathrm{BCP}$ is as chemosensitive as breast cancer in non-pregnant women [33]. It is recommended to dose chemotherapy according to the actual weight, using the general doses [10]. Supportive therapy can be given as indicated during pregnancy, but it should be kept to a minimum. Since methylprednisolone or hydrocortisone are extensively metabolized in the placenta, and relatively little reaches the foetal compartment, these steroids are preferred over beta/dexamethasone. Therefore, sequential regimens are indicated during pregnancy [30].

Chemotherapy should be started not before the end of the first trimester and should be stopped around the 35th week of gestation to allow for a 2-3-week chemotherapy-free interval prior to delivery and to allow for a term delivery $(>37$ th week). Children exposed to chemotherapy in utero seem to have no adverse outcome when compared to age-matched children, in the short and the long run [9, 34]. However, close monitoring of the pregnancy and an exact determination of the gestational age prior to start of the therapy are indicated.

The percentage of breast cancer patients with a HER2-positive tumour is higher in young women. Our data have shown that around $1 / 3$ of the patients with BCP had a HER2-positive disease. The use of trastuzumab during pregnancy is not advocated, as the majority of cases treated accidentally with trastuzumab during pregnancy showed an oligo-anhydramnios [35]. Recent data from the HERA study showed that, in the 16 pregnancies that occurred while treated with trastuzumab or up to 3 months after the end of trastuzumab treatment, no oligohydramnios occurred in the 5 women who continued pregnancy [36]. However, the spontaneous abortion rate was high at $25 \%$. None of these patients was exposed for longer than 2 months and all were exposed during the first trimester. Comparing these data with the data from the case reports, it seems that the duration and timing of trastuzumab is important. Nevertheless, the data do not support the use of trastuzumab during pregnancy. Today, most patients receive trastuzumab in addition to chemotherapy, or at least in addition to the taxane, if a sequential regimen has been chosen. But, so far, it has not been shown that the early start of trastuzumab is significantly superior to the start after completing chemotherapy as in the HERA study $[37,38]$.

Other anti-HER2 agents such as lapatinib or pertuzumab, which are currently investigated within clinical trials for early breast cancer, are not indicated during pregnancy. 
None of the experimental agents currently under investigation in metastatic breast cancer are indicated to be used in early breast cancer patients, with or without pregnancy.

Endocrine therapy, e.g. tamoxifen, should not be given during pregnancy. The risk to induce foetal malformations such as urogenital syndromes as reported in the literature is high and should be avoided [39].

\section{Obstetrical Considerations}

Timing is very important in treating BCP patients. When to start treatment, when to deliver, when to continue systemic treatment, surgery first or chemotherapy first; these questions have to be answered in the light of the individual situation. A checklist for the care of pregnant patients with breast cancer was recently proposed [12]. In general, preterm delivery has to be avoided in order reduce the long-term consequences for the infant. The morbidity and mortality risk is higher in preterm-delivered infants. However, the majority of women with cancer during pregnancy will be delivered prior to the estimated delivery date, especially when the decision has been taken to start systemic therapy outside pregnancy $[9,11]$. There are several reports indicating that some obstetrical complications are higher in women with BCP [11]. Is this observation real or pure chance because this is the way data have been captured? More data are still needed. Theoretically, pre-eclampsia may be more common in BCP patients treated with chemotherapy, but so far, no actual correlation between pre-eclampsia and chemotherapy application has been found [40].

\section{Prognosis}

It has been argued that the prognosis of BCP is inferior to that of non-pregnant women at the same stage and age. However, this will only be answered with large matched-pair control studies of high quality, to avoid a selection bias and to account for prognostic factors. Age is known to be an important prognostic factor, besides biological markers [7]. The Norwegian cancer registry showed that BCP does not have an inferior prognosis; however, to account for prognostic factors, breast cancer diagnosed during lactation had an increased risk of cause-specific death. Despite this unsolved matter, it is of utmost importance not to undertreat women with BCP [7].

Termination of pregnancy in the first trimester has so far not improved the prognosis of BCP. There are data that suggest the opposite, but it remains a personal decision. Under some rare circumstances, e.g., if the diagnosis is made very early in pregnancy and there is a strong indication not to delay chemotherapy, termination may be considered.

\section{Conclusions}

BCP can be treated closely to the standards for non-pregnant women. However, the treatment of such women is a challenge and the decision for the right (systemic) therapy within the whole breast cancer therapy concept (neoadjuvant vs. adjuvant; chemotherapy yes vs. no; taxane yes vs. no; early delivery yes vs. no; trastuzmab if indicated to be started after delivery; mastectomy vs. breast conservation; sentinel node biopsy vs. axillary dissection) needs to be taken within a larger multidisciplinary team of breast cancer specialists supporting the foetal specialist, obstetrician and neonatologist to take the best decision. At the end of the day, BCP still requires an individual treatment decision. Registries such as the ones by the German Breast Group (www.germanbreastgroup.de/ pregnancy) or the European Society of Gynaecological Oncology (ESGO) (www.cancerinpregnancy.org) need to be supported, and collaborations to be continued.

\section{Disclosure Statement}

F.A. is senior clinical investigator for the Research Fund-Flanders.

\section{References}

1 Stensheim H, Moller B, van Dijk T, Fossa SD: Cause-specific survival for women diagnosed with cancer during pregnancy or lactation: a registrybased cohort study. J Clin Oncol 2009;27:45-51.

$>2$ Andersson TM, Johansson AL, Hsieh CC, Cnattingius S, Lambe M: Increasing incidence of pregnancy-associated breast cancer in Sweden. Obstet Gynecol 2009;114:568-572.

3 Matthews TJ, Hamilton BE: Delayed childbearing: more women are having their first child later in life. NCHS Data Brief 2009;21:1-8.

4 Loibl S, Amant F, Kaufmann M, et al.: 313 patients with breast cancer during pregnancy - a prospective and retrospective registry (GBG-20 / BIG0203). Clin Cancer Res 2010;70(suppl 24):abstr S6-2.
${ }_{5}$ Collins LC, Marotti JD, Gelber S, Cole K, Ruddy K, Kereakoglow S, Brachtel EF, Schapira L, Come SE, Winer EP, Partridge AH: Pathologic features and molecular phenotype by patient age in a large cohort of young women with breast cancer. Breast Cancer Res Treat 2012;131:1061-1066.

-6 Azim HA Jr, Michiels S, Bedard PL, Singhal SK, Criscitiello C, Ignatiadis M, Haibe-Kains B, Piccart MJ, Sotiriou C, Loi S: Elucidating prognosis and biology of breast cancer arising in young women using gene expression profiling. Clin Cancer Res 2012;18:1341-1351.
7 Anders CK, Hsu DS, Broadwater G, et al.: Young age at diagnosis correlates with worse prognosis and defines a subset of breast cancers with shared patterns of gene expression. J Clin Oncol 2008;26:3324-3330.

8 Murphy CG, Mallam D, Stein S, Patil S, Howard J, Sklarin N, Hudis CA, Gemignani ML, Seidman AD: Current or recent pregnancy is associated with adverse pathologic features but not impaired survival in early breast cancer. Cancer 2011, in press.

9 Loibl S, von Minckwitz G, Gwyn K, Ellis P, Blohmer JU, Schlegelberger B, Keller M, Harder S, Theriault RL, Crivellari D, Klingebiel T, Louwen F, Kaufmann M: Breast carcinoma during pregnancy. International recommendations from an expert meeting. Cancer 2006;106:237-246. 
10 Amant F, Deckers S, Van Calsteren K, Loibl S, Halaska M, Brepoels L, Beijnen J, Cardoso F, Gentilini O, Lagae L, Mir O, Neven P, Ottevanger N, Pans S, Peccatori F, Rouzier R, Senn HJ, Struikmans H, Christiaens MR, Cameron D, Du Bois A: Breast cancer in pregnancy: recommendations of an international consensus meeting. Eur J Cancer 2010;46:3158-3168.

11 Van Calsteren K, Heyns L, De Smet F, et al.: Cancer during pregnancy: an analysis of 215 patients emphasizing the obstetrical and the neonatal outcomes. J Clin Oncol 2010;28:683-689.

-12 Amant F, Loibl S, Neven P, van Calsteren K: Breast cancer in pregnancy. Lancet 2012;379:570-579.

13 Nettleton J, Long J, Kuban D, Wu R, Shaefffer J, El-Mahdi A: Breast cancer during pregnancy: quantifying the risk of treatment delay. Obstet Gynecol 1996;87:414-418.

14 Ahn BY, Kim HH, Moon WK, Pisano ED, Kim HS, Cha ES, et al.: Pregnancy- and lactation-associated breast cancer: mammographic and sonographic findings. J Ultrasound Med 2003;22:491-497.

$\checkmark 15$ McCollough CH, Schueler BA, Atwell TD, Braun NN, Regner DM, Brown DL, et al.: Radiation exposure and pregnancy: when should we be concerned? Radiographics 2007;27:909-917.

16 Rajaraman P, Simpson J, Neta G, Berrington de Gonzalez A, Ansell P, Linet MS, Ron E, Roman E: Early life exposure to diagnostic radiation and ultrasound scans and risk of childhood cancer: case-control study. BMJ 2011;342:d472.

17 Kanal E, Barkovich AJ, Bell C, Borgstede JP, Bradley WG Jr, Froelich JW, et al.: ACR guidance document for safe MR practices: 2007. AJR Am J Roentgenol 2007;188:1447-1474.

18 www.nccn.org/professionals/physician_gls/pdf/ breast.pdf.

19 www.ago-online.del download/unprotected/ g_mamma_11_1_0_12_breast_cancer_specific_ situations.pdf.

20 Dominici LS, Kuerer HM, Babiera G, Hahn KM, Perkins G, Middleton L, et al.: Wound complications from surgery in pregnancy-associated breast cancer (PABC). Breast Dis 2010;31:1-5.

21 Gentilini O, Cremonesi M, Toesca A, Colombo N, Peccatori F, Sironi R, Sangalli C, Rotmensz N, Pedroli G, Viale G, Veronesi P, Galimberti V, Goldhirsch A, Veronesi U, Paganelli G: Sentinel lymph node biopsy in pregnant patients with breast cancer. Eur J Nucl Med Mol Imaging 2010;37:7883.
22 Khera SY, Kiluk JV, Hasson DM, Meade TL, Meyers MP, Dupont EL, et al.: Pregnancy-associated breast cancer patients can safely undergo lymphatic mapping. Breast J 2008:14:250-254.

23 Pruthi S, Haakenson C, Brost BC, Bryant K, Reid JM, Singh R, Netzel B, Boughey JC, Degnim AC: Pharmacokinetics of methylene blue dye for lymphatic mapping in breast cancer - implications for use in pregnancy. Am J Surg 2011;201:70-75.

24 Ruo Redda MG, Verna R, Guarneri A, Sannazzari GL: Timing of radiotherapy in breast cancer conserving treatment. Cancer Treat Rev 2002;28:5-10.

$25 \mathrm{Kal} \mathrm{HB}$, Struikmans H: Radiotherapy during pregnancy: fact and fiction. Lancet Oncol 2005;6:328-333.

26 Stovall M, Blackwell CR, Cundiff J, Novack DH, Palta JR, Wagner LK, et al.: Fetal dose from radiotherapy with photon beams: report of AAPM Radiation Therapy Committee Task Group No. 36. Med Phys 1995;22:63-82.

27 Rastogi P, Anderson SJ, Bear HD, Geyer CE, Kahlenberg MS, Robidoux A, Margolese RG, Hoehn JL, Vogel VG, Dakhil SR, Tamkus D, King KM, Pajon ER, Wright MJ, Robert J, Paik S, Mamounas EP, Wolmark N: Preoperative chemotherapy: updates of National Surgical Adjuvant Breast and Bowel Project Protocols B-18 and B-27. J Clin Oncol 2008;26:778-785.

28 Bonilla L, Ben-Aharon I, Vidal L, Gafter-Gvili A, Leibovici L, Stemmer SM: Dose-dense chemotherapy in nonmetastatic breast cancer: a systematic review and meta-analysis of randomized controlled trials. J Natl Cancer Inst 2010;102:1845-1854.

29 Huober J, von Minckwitz G, Denkert C, Tesch H, Weiss E, Zahm DM, Belau A, Khandan F, Hauschild M, Thomssen C, Högel B, Darb-Esfahani S, Mehta K, Loibl S: Effect of neoadjuvant anthracycline-taxane-based chemotherapy in different biological breast cancer phenotypes: overall results from the GeparTrio study. Breast Cancer Res Treat 2010;124:133-140.

30 Eiermann W, Pienkowski T, Crown J, Sadeghi S, Martin M, Chan A, Saleh M, Sehdev S, Provencher L, Semiglazov V, Press M, Sauter G, Lindsay MA, Riva A, Buyse M, Drevot P, Taupin H, Mackey JR: Phase III study of doxorubicin/cyclophosphamide with concomitant versus sequential docetaxel as adjuvant treatment in patients with human epidermal growth factor receptor 2-normal, node-positive breast cancer: BCIRG-005 trial. J Clin Oncol 2011;29:3877-3884.

31 Mir O, Berveiller P, Goffinet F, et al.: Taxanes for breast cancer during pregnancy: a systematic review. Ann Oncol 2010;21:425-426.
2 Van Calsteren K, Verbesselt R, Devlieger R, De Catte L, Chai D, Van Bree R, Heyns L, Beijnen J, Demarsin S, de Bruijn E, de Hoon J, Amant F: Transplacental transfer of paclitaxel, docetaxel, carboplatin, and trastuzumab in a baboon model. Int J Gynecol Cancer 2010;20:1456-1464.

33 Rouzier R, Werkoff G, Uzan C, Mir O, Gligorov J, Selleret L, Goffinet F, Goldwasser F, Treluyer JM, Uzan S, Delaloge S: Pregnancy-associated breast cancer is as chemosensitive as non-pregnancy-associated breast cancer in the neoadjuvant setting. Ann Oncol 2011:22:1582-1587.

34 Amant F, Van Calsteren K, Halaska MJ, Gziri MM, Hui W, Lagae L, Willemsen MA, Kapusta L, Van Calster B, Wouters H, Heyns L, Han SN, Tomek V, Mertens L, Ottevanger PB: Long-term cognitive and cardiac outcomes after prenatal exposure to chemotherapy in children aged 18 months or older: an observational study. Lancet Oncol 2012;13:256-264.

35 Loibl S: New therapeutic options for breast cancer during pregnancy. Breast Care (Basel) 2008;3:171176.

36 Azim HA Jr, Metzger-Filho O, de Azambuja E, Loibl S, Focant F, Gresko E, Arfi M, Piccart-Gebhart M: Pregnancy occurring during or following adjuvant trastuzumab in patients enrolled in the HERA trial (BIG 01-01). Breast Cancer Res Treat 2012;133:387-391.

37 Gianni L, Dafni U, Gelber RD, Azambuja E, Muehlbauer S, Goldhirsch A, Untch M, Smith I, Baselga J, Jackisch C, Cameron D, Mano M, Pedrini JL, Veronesi A, Mendiola C, Pluzanska A, Semiglazov V, Vrdoljak E, Eckart MJ, Shen Z, Skiadopoulos G, Procter M, Pritchard KI, PiccartGebhart MJ, Bell R; Herceptin Adjuvant (HERA) Trial Study Team: Treatment with trastuzumab for 1 year after adjuvant chemotherapy in patients with HER2-positive early breast cancer: a 4-year follow-up of a randomised controlled trial. Lancet Oncol 2011;12:236-244.

38 Perez EA, Suman VJ, Davidson NE, Gralow JR, Kaufman PA, Visscher DW, Chen B, Ingle JN, Dakhil SR, Zujewski J, Moreno-Aspitia A, Pisansky TM, Jenkins RB: Sequential versus concurrent trastuzumab in adjuvant chemotherapy for breast cancer. J Clin Oncol 2011;29:4491-4497.

39 Tewari K, Bonebrake RG, Asrat T, Shanberg AM: Ambiguous genitalia in infant exposed to tamoxifen in utero. Lancet 1997:350:183.

40 Massey-Skatulla L, Loibl S, Schauf B, Müller T: Pre-eclampsia following chemotherapy for breast cancer during pregnancy: case report and review of the literature. Arch Gynecol Obstet 2012, in press. 